\title{
The effect of curvature on transient analysis of laminated composite cylindrical shells on elastic foundation
}

\author{
Elastik zemin üzerine oturan tabakalı kompozit silindirik kabukların \\ zorlanmıș titreşim analizi üzerine eğriliğin etkisi
}

\author{
Ali DOĞAN ${ }^{*}$ (iD) \\ ${ }^{1}$ Department of Civil Engineering, Faculty of Engineering and Natural Sciences, Iskenderun Technical University, Hatay, Turkey. \\ ali.dogan@iste.edu.tr
}

Received/Geliș Tarihi: 18.07.2017, Accepted/Kabul Tarihi: 16.10.2017

doi: $10.5505 /$ pajes. 2017.60476

* Corresponding author/Yazıșllan Yazar Research Article/Araștırma Makalesi

\section{Abstract}

This study presents the effect of curvature ratio on transient vibration analysis of simply supported antisymmetric thick cross-ply laminated composite shells (LCS) on elastic foundation. In the analysis, the foundation is modeled with two parameters. These models are Pasternak and Winkler models. The equation of motion for laminated rectangular shells resting on elastic foundation is obtained through Hamilton's principle. The analysis is achieved in Laplace domain. By using modified Durbin's algorithm, calculations are transformed from Laplace domain to the time domain. The numerical results are presented in the form of graphics.

Keywords: Laminated composite, Transient vibration, Curvature effect, Elastic foundation, Shear deformation shell theory

\section{Introduction}

Recently, due to the many paramount properties advanced composite materials such as laminated shells are found an application area in the engineering projects. Tremendous researches have been performed on the LCS to clarify the advantages of using these types of materials. One of the focused topics in research subject is the transient vibration analysis of composite shells on elastic foundation.

In this paper, effect of curvature ratio and Winkler-Pasternak soil parameters on transient vibrations of anti-symmetrically cross-ply LCS on elastic foundation are analyzed (Figure 1). The equation of motion for laminated rectangular shells resting on elastic foundation is obtained through Hamilton's principle. The closed form solutions are obtained by using Navier technique. The analysis is achieved in Laplace domain. By using modified Durbin's algorithm [1], calculations are transformed to Laplace domain to the time domain.

Reissner theory [2] is one of the theories which include the shear deformation effect and many researchers have studied on the dynamic analysis of LCP by using Reissner theory. Many researchers have studies the free vibration of laminated composite shells [3]-[5],[7]. Dogan and Arslan [6] investigated the effect of dimension on mode-shapes of composite shells. Sofiyev [8] studied the buckling of a cross-ply laminated nonhomogeneous orthotropic composite cylindrical thin shell under time dependent external pressure.
Öz

Bu çalıșmada, elastik zemin üzerine oturan basit mesnetli antisimetrik çapraz-katlı dizilimli tabakalı kompozit silindirik kalın kabukların (LCS), zorlanmıs titreșim analizi üzerine eğrilik oranının etkisi sunulmaktadır. Bu analizlerde, zemin iki parametre ile modellendi. Bu modeller Pasternak ve Winkler modelleridir. Hamilton prensipleri ile elastik zemin üzerindeki tabakalı kompozit dikdörtgen kabukların hareket denklemleri elde edilmistir. Analizler, Laplace alanında elde edilmiştir. Modifiye Durbin yöntemi ile çözümler Laplace alanından zaman alanına dönüstürülmüstür. Sayısal sonuçlar grafikler șeklinde sunulmuștur

Anahtar kelimeler: Tabakalı kompozit, Zorlanmıș titreșim, Eğrilik etkisi, Elastik zemin, Kayma deformasyon kabuk teorisi

Qatu [9] and Reddy [10] used energy function to develop governing equations of LCS and presented studies including the effect of shear deformation for composite shells. Toh, Gong and Shim [11] investigated the transient stresses generated by low velocity impact on orthotropic laminated cylindrical shells. Temel and Sahan [12] studied on the Transient analysis of orthotropic viscoelastic thick plates. Hui-Shen et al. [13] investigated dynamic behaviour of LCP on elastic foundation under thermomechanical loading. Pasternak [14] presented new method calculation for flexible substructures and modeled the foundation with two parameters. Akavci et al. [15] examined dynamic behavior of LCP on elastic foundation by using First-order Shear Deformation Theory (FSDT). Civalek [16] studied nonlinear dynamic response of laminated plates resting on nonlinear elastic foundations by the discrete singular convolution-differential quadrature coupled approaches.

\section{Materials and Methods}

A lamina is produced with the isotropic homogenous fibers and matrix materials. Any point on a fiber and/or on matrix and/or on matrix-fiber interface has crucial effect on the stiffness of the lamina (Figure 2-3). Due to the big variation on the properties of lamina from point to point, macro-mechanical properties.of lamina are determined based on the statistical approach. According to FSDT, the transverse normal do not remain perpendicular to the mid-surface after deformation. It will be assumed that the deformation of the plates and shells is completely determined by the displacement of its middle surface. 


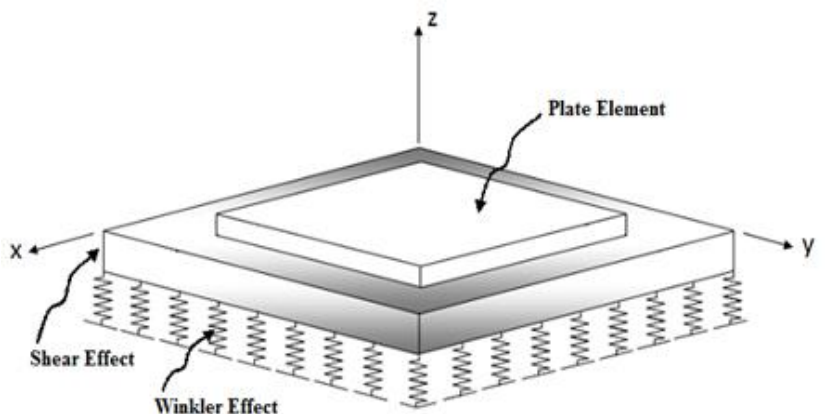

Figure 1: Laminated composite plate on elastic foundation.

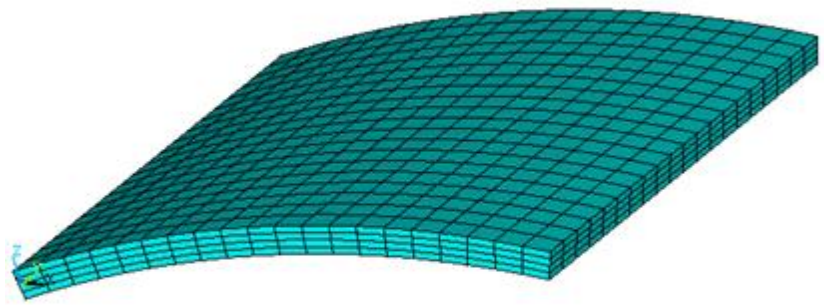

Figure 2: Laminated composite cylindrical shell [17].

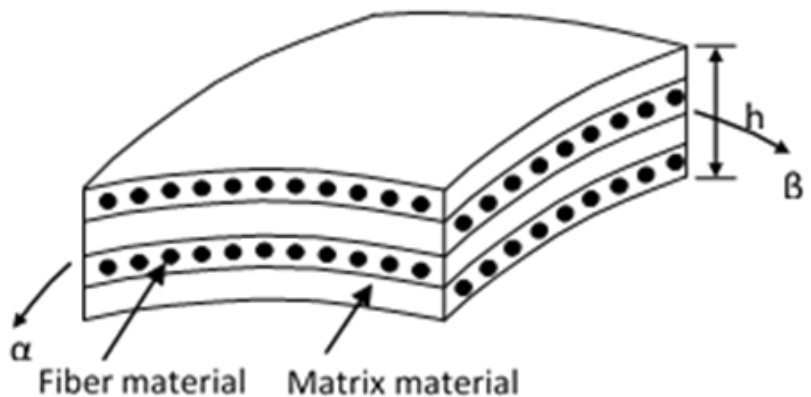

Figure 3: Fiber and matrix materials in laminated composite shell.

Stress-strain equations for nth layer of laminated shell can be expressed in the lamina coordinates as follow,

$$
\left[\begin{array}{c}
\sigma_{\alpha} \\
\sigma_{\beta} \\
\sigma_{z} \\
\tau_{\beta z} \\
\tau_{\alpha z} \\
\tau_{\alpha \beta}
\end{array}\right]=\left[\begin{array}{cccccc}
\bar{Q}_{11} & \bar{Q}_{12} & \bar{Q}_{13} & 0 & 0 & \bar{Q}_{16} \\
\bar{Q}_{12} & \bar{Q}_{22} & \bar{Q}_{23} & 0 & 0 & \bar{Q}_{26} \\
\bar{Q}_{13} & \bar{Q}_{23} & \bar{Q}_{33} & 0 & 0 & \bar{Q}_{36} \\
0 & 0 & 0 & \bar{Q}_{44} & \bar{Q}_{45} & 0 \\
0 & 0 & 0 & \bar{Q}_{45} & \bar{Q}_{55} & 0 \\
\bar{Q}_{16} & \bar{Q}_{26} & \bar{Q}_{36} & 0 & 0 & \bar{Q}_{66}
\end{array}\right]\left[\begin{array}{c}
\varepsilon_{\alpha} \\
\varepsilon_{\beta} \\
\varepsilon_{z} \\
\gamma_{\beta z} \\
\gamma_{\alpha z} \\
\gamma_{\alpha \beta}
\end{array}\right]
$$

The displacement based on shell theory can be written as

$$
\begin{gathered}
\mathrm{u}(\alpha, \beta, \mathrm{z})=\mathrm{u}_{0}(\alpha, \beta)+\mathrm{z} \varphi_{\mathrm{x}}(\alpha, \beta) \\
\mathrm{v}(\alpha, \beta, \mathrm{z})=\mathrm{v}_{0}(\alpha, \beta)+\mathrm{z} \varphi_{\mathrm{y}}(\alpha, \beta) \\
\mathrm{w}(\alpha, \beta, \mathrm{z})=\mathrm{w}_{0}(\alpha, \beta)
\end{gathered}
$$

Where $\mathrm{u}, \mathrm{v}, \mathrm{w}, \varphi_{\alpha}$ and $\varphi_{\beta}$ are displacements and rotations in $\alpha$, $\beta, \mathrm{z}$ direction, orderly. uo, vo and wo are mid-plane displacements.

$$
\begin{aligned}
& \varepsilon_{\alpha}=\frac{1}{\left(1+z / R_{\alpha}\right)}\left(\varepsilon_{0 \propto}+z \kappa_{\alpha}\right) \\
& \varepsilon_{\beta}=\frac{1}{\left(1+z / R_{\beta}\right)}\left(\varepsilon_{0 \beta}+z \kappa_{\beta}\right) \\
& \varepsilon_{\alpha \beta}=\frac{1}{\left(1+z / R_{\alpha}\right)}\left(\varepsilon_{0 \propto \beta}+z \kappa_{\alpha \beta}\right) \\
& \varepsilon_{\beta \alpha}=\frac{1}{\left(1+z / R_{\beta}\right)}\left(\varepsilon_{0 \beta \alpha}+z \kappa_{\beta \alpha}\right) \\
& \gamma_{\alpha z}=\frac{1}{\left(1+z / R_{\alpha}\right)}\left(\gamma_{0 \propto z}+z\left(\psi_{\alpha} / R_{\alpha}\right)\right) \\
& \gamma_{\beta z}=\frac{1}{\left(1+z / R_{\beta}\right)}\left(\gamma_{0 \beta z}+z\left(\psi_{\beta} / R_{\beta}\right)\right) \\
& \varepsilon_{0 \alpha}=\frac{1}{A} \frac{\partial u_{0}}{\partial \alpha}+\frac{v_{0}}{A B} \frac{\partial A}{\partial \beta}+\frac{w_{0}}{R_{\alpha}} \\
& \varepsilon_{0 \beta}=\frac{1}{B} \frac{\partial v_{0}}{\partial \beta}+\frac{u_{0}}{A B} \frac{\partial B}{\partial \alpha}+\frac{w_{0}}{R_{\beta}} \\
& \varepsilon_{0 \alpha \beta}=\frac{1}{A} \frac{\partial v_{0}}{\partial \alpha}-\frac{u_{0}}{A B} \frac{\partial A}{\partial \beta}+\frac{w_{0}}{R_{\alpha \beta}} \\
& \varepsilon_{0 \beta \alpha}=\frac{1}{B} \frac{\partial u_{0}}{\partial \beta}-\frac{v_{0}}{A B} \frac{\partial B}{\partial \alpha}+\frac{w_{0}}{R_{\alpha \beta}} \\
& \gamma_{0 \alpha z}=\frac{1}{A} \frac{\partial w_{0}}{\partial \alpha}-\frac{u_{0}}{R_{\alpha}}-\frac{v_{0}}{R_{\alpha \beta}}+\psi_{\alpha} \\
& \gamma_{0 \beta z}=\frac{1}{B} \frac{\partial w_{0}}{\partial \beta}-\frac{v_{0}}{R_{\beta}}-\frac{u_{0}}{R_{\alpha \beta}}+\psi_{\beta} \\
& \kappa_{\alpha}=\frac{1}{A} \frac{\partial \psi_{\alpha}}{\partial \alpha}+\frac{\psi_{\beta}}{A B} \frac{\partial A}{\partial \beta} \\
& \kappa_{\beta}=\frac{1}{B} \frac{\partial \psi_{\beta}}{\partial \beta}+\frac{\psi_{\alpha}}{A B} \frac{\partial B}{\partial \alpha} \\
& \kappa_{\alpha \beta}=\frac{1}{A} \frac{\partial \psi_{\beta}}{\partial \alpha}-\frac{\psi_{\alpha}}{A B} \frac{\partial A}{\partial \beta} \\
& \kappa_{\beta \alpha}=\frac{1}{B} \frac{\partial \psi_{\alpha}}{\partial \beta}-\frac{\psi_{\beta}}{A B} \frac{\partial B}{\partial \alpha}
\end{aligned}
$$

Potential energy can define as

$$
\Pi=U-W
$$

and Lagrangian funtion is

$$
L=T-\Pi
$$

Lagrangian function is set to zero and the Hamilton principle is applied to the Lagrange equation. Hamilton's principle can be used to find equation of motion for shell structures.

$$
\delta \int_{t_{1}}^{t_{2}}\left(T+W-\left(U+U_{F}\right) d t=0\right.
$$

where $\mathrm{T}$ is the kinetic energy of the structure

$$
T=\frac{\rho}{2} \int\left\{\frac{\partial u}{\partial t}\right\}^{2}+\left\{\frac{\partial v}{\partial t}\right\}^{2}+\left\{\frac{\partial w}{\partial t}\right\}^{2} d \alpha d \beta d z
$$


$\mathrm{W}$ is the work of the external forces

$$
\begin{gathered}
W=\int_{x} \int_{y}\left(q_{\alpha} u_{0}+q_{\beta} v_{0}+q_{n} w_{0}+m_{\alpha} \psi_{\alpha}\right. \\
\left.+m_{\beta} \psi_{\beta}\right) A B d \alpha d \beta
\end{gathered}
$$

in which $\mathrm{q}_{\alpha}, \mathrm{q}_{\beta}, \mathrm{q}_{\mathrm{z}}, \mathrm{m}_{\alpha}, \mathrm{m}_{\beta}$ are the external forces and moments, respectively. $U$ is the strain energy and UF is the spring strain energy defined as,

$$
\begin{gathered}
U=\frac{1}{2} \int_{V}\left\{\sigma_{\alpha} \varepsilon_{\alpha}+\sigma_{\beta} \varepsilon_{\beta}+\sigma_{z} \varepsilon_{z}+\sigma_{\alpha \beta} \gamma_{\alpha \beta}+\sigma_{\alpha z} \gamma_{\alpha z}\right. \\
\left.+\sigma_{\beta z} \gamma_{\beta z}\right\} d V \\
U_{F}=\frac{1}{2} \int\left(k_{0} w^{2}+k_{1}\left[\left(\frac{\partial w}{\partial \alpha}\right)^{2}+\left(\frac{\partial w}{\partial \beta}\right)^{2}\right]\right) d \alpha d \beta
\end{gathered}
$$

Where $\mathrm{k}_{0}$ is the Winkler foundation parameter and $\mathrm{k}_{1}$ is the Pasternak foundation parameter. Solving equation 2 gives set of equations called equations of motion for shell structures. This gives equation 12 in simplified form as,

$$
\begin{gathered}
\frac{\partial}{\partial \alpha}\left(B N_{\alpha}\right)+\frac{\partial}{\partial \beta}\left(A N_{\beta \alpha}\right)+\frac{\partial A}{\partial \beta} N_{\alpha \beta}-\frac{\partial B}{\partial \alpha} N_{\beta}+\frac{A B}{R_{\alpha}} Q_{\alpha}+\frac{A B}{R_{\alpha \beta}} Q_{\beta} \\
+A B q_{\alpha}=A B\left(\bar{I}_{1} \ddot{u}^{2}+\bar{I}_{1} \ddot{\Psi}_{\alpha}{ }^{2}\right) \\
\frac{\partial}{\partial x}\left(A N_{y}\right)+\frac{\partial}{\partial x}\left(B N_{x y}\right)+\frac{\partial B}{\partial x} N_{y x}-\frac{\partial A}{\partial y} N_{x}+\frac{A B}{R_{y}} Q_{y}+\frac{A B}{R_{x y}} Q_{x} \\
+A B q_{y}=A B\left(\bar{I}_{1} \ddot{v}^{2}+\bar{I}_{2} \ddot{\Psi}_{y}{ }^{2}\right) \\
-A B\left(\frac{N_{x}}{R_{x}}+\frac{N_{y}}{R_{y}}+\frac{N_{x y+} N_{y x}}{R_{x y}}\right)+\frac{\partial}{\partial x}\left(B Q_{x}\right)+\frac{\partial}{\partial y}\left(A Q_{y}\right)+A B q_{z} \\
+k_{0} w+k_{1} \Delta^{2} w=A B\left(\bar{I}_{1} \ddot{w}^{2}\right) \\
\frac{\partial}{\partial x}\left(B M_{x}\right)+\frac{\partial}{\partial y}\left(A M_{y x}\right)+\frac{\partial A}{\partial y} M_{x y}-\frac{\partial B}{\partial x} M_{y}-A B Q_{x}+\frac{A B}{R_{x}} P_{x} \\
+A B m_{x}=A B\left(\bar{I}_{2} \ddot{u}^{2}+\bar{I}_{3} \ddot{\Psi}_{x}{ }^{2}\right) \\
\frac{\partial}{\partial y}\left(A M_{y}\right)+\frac{\partial}{\partial x}\left(B M_{x y}\right)+\frac{\partial B}{\partial x} M_{y x}-\frac{\partial A}{\partial y} M_{x}-A B Q_{y}+\frac{A B}{R_{y}} P_{y} \\
+A B m_{y}=A B\left(\bar{I}_{2} \ddot{v}^{2}+\bar{I}_{3} \ddot{\Psi}_{y}{ }^{2}\right)
\end{gathered}
$$

Equation 12 is defined as equation of motion for thick shell. Here, A and B equal zero. The force and moment resultants are

$$
\left[\begin{array}{c}
N_{\alpha} \\
N_{\beta} \\
N_{\alpha \beta} \\
N_{\beta \alpha} \\
M_{\alpha} \\
M_{\beta} \\
M_{\alpha \beta} \\
M_{\beta \alpha}
\end{array}\right]
$$$$
=\left[\begin{array}{llllllll}
\bar{A}_{11} & A_{12} & \bar{A}_{16} & A_{16} & \bar{B}_{11} & B_{12} & \bar{B}_{16} & B_{16} \\
A_{12} & \hat{A}_{22} & A_{26} & \hat{A}_{26} & B_{12} & \widehat{B}_{22} & B_{26} & \widehat{B}_{26} \\
\bar{A}_{16} & A_{26} & \bar{A}_{66} & A_{66} & \bar{B}_{16} & B_{26} & \bar{B}_{66} & B_{66} \\
A_{16} & \hat{A}_{26} & A_{66} & \hat{A}_{66} & B_{16} & \widehat{B}_{26} & B_{66} & \widehat{B}_{66} \\
\bar{B}_{11} & B_{12} & \bar{B}_{16} & B_{16} & \bar{D}_{11} & D_{12} & \bar{D}_{16} & D_{16} \\
B_{12} & \hat{B}_{22} & B_{26} & \hat{B}_{26} & D_{12} & \widehat{D}_{22} & D_{26} & \widehat{D}_{26} \\
\bar{B}_{16} & B_{26} & \bar{B}_{66} & B_{66} & \bar{D}_{16} & D_{26} & \bar{D}_{66} & D_{66} \\
B_{16} & \hat{B}_{26} & B_{66} & \hat{B}_{66} & D_{16} & \widehat{D}_{26} & D_{66} & \widehat{D}_{66}
\end{array}\right]\left[\begin{array}{c}
\varepsilon_{0 \alpha} \\
\varepsilon_{0 \beta} \\
\varepsilon_{0 \alpha \beta} \\
\varepsilon_{0 \beta \alpha} \\
\kappa_{\alpha} \\
\kappa_{\beta} \\
\kappa_{\alpha \beta} \\
\kappa_{\beta \alpha}
\end{array}\right]
$$

$$
\left[\begin{array}{l}
Q_{\alpha} \\
Q_{\beta} \\
P_{\alpha} \\
P_{\beta}
\end{array}\right]=\left[\begin{array}{llll}
\bar{A}_{55} & A_{45} & \bar{B}_{55} & B_{45} \\
A_{45} & \hat{A}_{44} & B_{45} & \hat{B}_{44} \\
\bar{B}_{55} & B_{45} & \bar{D}_{45} & D_{45} \\
B_{45} & \hat{B}_{44} & D_{45} & \widehat{D}_{66}
\end{array}\right]\left[\begin{array}{c}
\gamma_{0 \alpha z} \\
\gamma_{0 \beta z} \\
-\frac{\psi_{\alpha}}{R_{\alpha}} \\
\psi_{\beta} \\
R_{\beta}
\end{array}\right]
$$

Where,

$$
\begin{aligned}
& \bar{A}_{i j}=A_{\mathrm{ij}}-\mathrm{c}_{0} \mathrm{~B}_{\mathrm{ij}} \\
& \hat{A}_{i j}=A_{\mathrm{ij}}+\mathrm{c}_{0} \mathrm{~B}_{\mathrm{ij}} \\
& \bar{B}_{i j}=B_{\mathrm{ij}}-\mathrm{c}_{0} \mathrm{D}_{\mathrm{ij}} \\
& \hat{B}_{i j}=B_{\mathrm{ij}}+\mathrm{c}_{0} \mathrm{D}_{\mathrm{ij}} \\
& \bar{D}_{i j}=D_{\mathrm{ij}}-\mathrm{c}_{0} \mathrm{E}_{\mathrm{ij}} \\
& \widehat{D}_{i j}=D_{\mathrm{ij}}+\mathrm{c}_{0} \mathrm{E}_{\mathrm{ij}}
\end{aligned}
$$

$\mathrm{i}, \mathrm{j}=1,2,4,5,6$

$$
\begin{aligned}
& \mathrm{A}_{i j}=\sum_{k=1}^{N} \bar{Q}_{i j}{ }^{(k)}\left(h_{\mathrm{k}}-h_{\mathrm{k}-1}\right) \\
& \mathrm{B}_{i j}=\frac{1}{2} \sum_{k=1}^{N} \bar{Q}_{i j}{ }^{(k)}\left({h_{\mathrm{k}}}^{2}-{h_{\mathrm{k}-1}}^{2}\right) \\
& \mathrm{D}_{i j}=\frac{1}{3} \sum_{k=1}^{N} \bar{Q}_{i j}{ }^{(k)}\left({h_{\mathrm{k}}}^{3}-{h_{\mathrm{k}-1}}^{3}\right) \\
& \mathrm{E}_{i j}=\frac{1}{4} \sum_{k=1}^{N} \bar{Q}_{i j}{ }^{(k)}\left(h_{\mathrm{k}}{ }^{4}-h_{\mathrm{k}-1}{ }^{4}\right) \\
& i, j=1,2,6 \\
& \mathrm{~A}_{i j}=\sum_{k=1}^{N} K_{i} K_{j} \bar{Q}_{i j}{ }^{(k)}\left(h_{\mathrm{k}}-h_{\mathrm{k}-1}\right) \\
& \mathrm{B}_{i j}=\frac{1}{2} \sum_{k=1}^{N} K_{i} K_{j} \bar{Q}_{i j}{ }^{(k)}\left({h_{\mathrm{k}}}^{2}-h_{\mathrm{k}-1}{ }^{2}\right) \\
& \mathrm{D}_{i j}=\frac{1}{3} \sum_{k=1}^{N} K_{i} K_{j} \bar{Q}_{i j}{ }^{(k)}\left(h_{\mathrm{k}}{ }^{3}-h_{\mathrm{k}-1}{ }^{3}\right)
\end{aligned}
$$

$\mathrm{i}, \mathrm{j}=4,5$

$\mathrm{k}$ is Nth layer of the shell per unit midsurface area. Where the parameter $\mathrm{K}_{\mathrm{i}}$ and $\mathrm{K}_{\mathrm{j}}$ is the shear correction factor. Here, $\mathrm{K}$ is taken as 5/6. Co value and mass moment inertia terms are

$$
\begin{gathered}
\mathrm{c}_{0}=\left(\frac{1}{R_{\alpha}}-\frac{1}{R_{\beta}}\right) \\
{\left[I_{1}, I_{2}, I_{3}, I_{4}, I_{5}\right]=\mathrm{A}_{i j}=\sum_{k=1}^{N} \int_{h_{k-1}}^{h_{k}} \rho^{(k)}\left[1, z, z^{2}, z^{3}, z^{4}\right] d z} \\
\overline{I_{i}}=\left(I_{i}+I_{i+1}\left(\frac{1}{R_{\alpha}}-\frac{1}{R_{\beta}}\right)+\frac{I_{i+2}}{R_{\alpha} R_{\beta}}\right)
\end{gathered}
$$

$\rho^{(\mathrm{k})}$ is the mass density of the kth layer of the shell per unit midsurface area. The Navier type solution might be implemented to thick and thin shells. This type solution 
assumes that the displacement section of the shells can be denoted as sine and cosine trigonometric functions.

Assume a shell with shear diaphragm boundaries on all edges. For simply supported thick shells, boundary conditions can be arranged as follows:

$$
\begin{array}{ll}
N_{\alpha}=\mathrm{w}_{0}=\mathrm{v}_{0}=M_{\alpha}=\Psi_{\beta}=0 & \alpha=0, a \\
N_{\beta}=\mathrm{w}_{0}=\mathrm{u}_{0}=M_{\beta}=\Psi_{\alpha}=0 & \alpha=0, b
\end{array}
$$

The displacement functions of satisfied the boundary conditions apply;

$$
\begin{aligned}
& \mathrm{u}_{0}(\alpha, \beta, \mathrm{t})=\sum_{m=0}^{\infty} \sum_{n=0}^{\infty} U_{m n} \cos \left(\alpha_{m} \alpha\right) \sin \left(\beta_{n} \beta\right) \sin \left(\omega_{m n} t\right) \\
& v_{0}(\alpha, \beta, \mathrm{t})=\sum_{m=0}^{\infty} \sum_{n=0}^{\infty} V_{m n} \sin \left(\alpha_{m} \alpha\right) \cos \left(\beta_{n} \beta\right) \sin \left(\omega_{m n} t\right) \\
& w_{0}(\alpha, \beta, \mathrm{t})=\sum_{m=0}^{\infty} \sum_{n=0}^{\infty} W_{m n} \sin \left(\alpha_{m} \alpha\right) \sin \left(\beta_{n} \beta\right) \sin \left(\omega_{m n} t\right) \\
& \psi_{\alpha}(\alpha, \beta, \mathrm{t})=\sum_{m=0}^{\infty} \sum_{n=0}^{\infty} W_{m n} \cos \left(\alpha_{m} \alpha\right) \sin \left(\beta_{n} \beta\right) \sin \left(\omega_{m n} t\right) \\
& \psi_{\beta}(\alpha, \beta, \mathrm{t})=\sum_{m=0}^{\infty} \sum_{n=0}^{\infty} W_{m n} \sin \left(\alpha_{m} \alpha\right) \cos \left(\beta_{n} \beta\right) \sin \left(\omega_{m n} t\right)
\end{aligned}
$$

where $\alpha_{m}=m \pi / a, \beta_{n}=n \pi / b$.

Substituting the above equations into the equation of motion in matrix form,

$$
\begin{gathered}
{\left[\begin{array}{ccccc}
\mathrm{M}_{11} & 0 & 0 & \mathrm{M}_{14} & 0 \\
0 & \mathrm{M}_{22} & 0 & 0 & \mathrm{M}_{25} \\
0 & 0 & \mathrm{M}_{33} & 0 & 0 \\
\mathrm{M}_{41} & 0 & 0 & \mathrm{M}_{44} & 0 \\
0 & \mathrm{M}_{52} & 0 & 0 & \mathrm{M}_{55}
\end{array}\right]\left[\begin{array}{c}
\ddot{U}_{m n} \\
\ddot{V}_{m n} \\
\ddot{W}_{m n} \\
\ddot{\psi}_{\alpha m n} \\
\ddot{\psi}_{\beta m n}
\end{array}\right]} \\
+\left[\begin{array}{lllll}
\mathrm{K}_{11} & \mathrm{~K}_{12} & \mathrm{~K}_{13} & \mathrm{~K}_{14} & \mathrm{~K}_{15} \\
\mathrm{~K}_{21} & \mathrm{~K}_{22} & \mathrm{~K}_{23} & \mathrm{~K}_{24} & \mathrm{~K}_{25} \\
\mathrm{~K}_{31} & \mathrm{~K}_{32} & \mathrm{~K}_{33} & \mathrm{~K}_{34} & \mathrm{~K}_{35} \\
\mathrm{~K}_{41} & \mathrm{~K}_{42} & \mathrm{~K}_{43} & \mathrm{~K}_{44} & \mathrm{~K}_{45} \\
\mathrm{~K}_{51} & \mathrm{~K}_{52} & \mathrm{~K}_{53} & \mathrm{~K}_{54} & \mathrm{~K}_{55}
\end{array}\right]\left[\begin{array}{c}
U_{m n} \\
V_{m n} \\
W_{m n} \\
\psi_{\alpha m n} \\
\psi_{\beta m n}
\end{array}\right]=\left[\begin{array}{c}
P_{\beta} \\
-P_{n} \\
m_{\alpha} \\
m_{\beta}
\end{array}\right]
\end{gathered}
$$

Equation 23 can be arranged in a closed form as follows:

$$
\left[M_{m n}\right]\left\{\ddot{D}_{m n}\right\}+\left[K_{m n}\right]\left\{D_{m n}\right\}=\{P\}
$$

where $\left[\mathrm{M}_{\mathrm{mn}}\right],\left[\mathrm{K}_{\mathrm{mn}}\right],\{\mathrm{P}\}$ and $\{\mathrm{Dmn}\}$ are mass and stiffness matrices, load and unknown displacement vectors, respectively. By taking the Laplace transform with respect to time, the above complex equation can be reduced as linear relationship in Laplace domain as follows:

$$
\left\lceil z^{2}\left[M_{m n}\right]+\left[K_{m n}\right]\right\rceil\left\{\bar{D}_{m n}\right\}=\{\bar{P}\}
$$

where ( ) denotes parameters in Laplace domain and $\mathrm{z}$ is the Laplace parameter. Initial conditions for the displacement and velocity vectors are taken be zero. As a special application for the current study, vibration analysis might be performed by simply eliminating the loads and substituting the Laplace parameter " $z$ " with " $i \omega$ ". Therefore, eigenvalues can present us the natural frequencies. The calculations are transformed from Laplace domain to time domain using the Durbin's algorithm.

Differential equations can be solved with the help of the numerical operation method which is Laplace transformation method. In this approach it is possible to remove the time parameter by using Laplace transformation. Non-time dependent differential equations can easily be solved with numerical methods. The solutions obtained in the Laplace space can be transformed into time space using Durbin's modified using inverse Laplace transform technique.

\section{Numerical solutions and discussions}

In current research, forced vibration analyses of symmetric and anti-symmetric LCS on elastic foundation are investigated. Navier solution procedure for dynamic response of LCS is obtained. The computer programs have been prepared using Mathematica [18] program separately for the solution of the dynamic response of LCS on elastic foundation.

In this part, different numerical problems are given about dynamic analysis of LCS. Firstly, prepared computer program was validated and this problem is investigated under an impulsive load. The effects of the R/a ratios and foundation parameters on dynamic response are also investigated.

In the analysis, following parameters are studied for Winkler and Pasternak foundation as;

$$
\mathrm{k}_{0}=\frac{K_{0} a^{4}}{E_{2} h^{3}}, \mathrm{k}_{1}=\frac{K_{1} a^{2}}{E_{2} h^{3}}
$$

As a first example, a simply supported anti-symmetric $\left[0^{\circ} / 90^{\circ}\right]$ laminated composite plate subjected to uniformly distributed step impulsive load is considered (Figure 4). The results obtained have been compared in Figure 5. In numerical calculations for forced vibration of LCP, the material and geometrical properties are defined as: $\mathrm{a}=1 \mathrm{~m}, \mathrm{a} / \mathrm{b}=1, \mathrm{a} / \mathrm{h}=10$, $\rho=2000 \mathrm{~kg} / \mathrm{m}^{3}, \mathrm{E}_{1}=25 \times 10^{3} \mathrm{MPa}, \mathrm{E}_{1} / \mathrm{E}_{2}=25, \mathrm{G}_{12} / \mathrm{E}_{2}=\mathrm{G}_{13} / \mathrm{E}_{2}=$ $0.5, \mathrm{G}_{23} / \mathrm{E}_{2}=0.2, \mathrm{v}=0.25$. A uniformly distributed step impulsive load, $\mathrm{q}_{\mathrm{o}}=1000 \mathrm{~N} / \mathrm{m}^{2}$, is applied on the plate. Laplace transform parameter $(\mathrm{N}=512)$ and time increment value of $(\mathrm{dt}=0.00064)$ have been used.

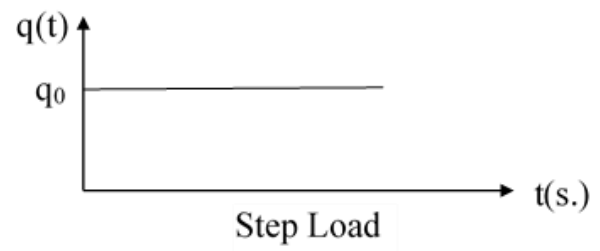

Figure 4: Dynamic load.

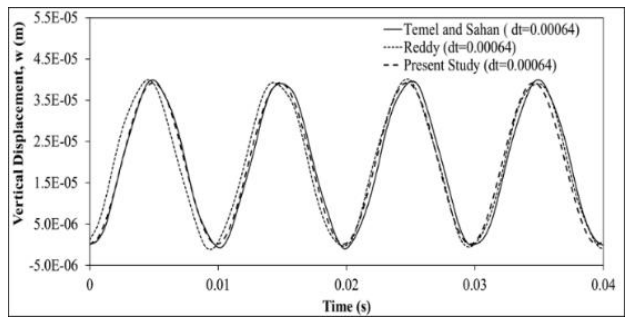

Figure 5: Vertical displacement versus time for [0/90].

It can be seen from Figure 5 that the results between current study and other studies for the vertical displacement values are very close to each other. 
In second example, the material and geometrical properties are defined as: $\mathrm{a}=1 \mathrm{~m}, \mathrm{a} / \mathrm{b}=1 ; \mathrm{a} / \mathrm{h}=10 ; \mathrm{R} / \mathrm{a}=\infty$ (plate), $10,1,0.5$, 0.382 (cylinder), $\rho=2000 \mathrm{~kg} / \mathrm{m}^{3}, \mathrm{E}_{1}=25 \times 10^{3} \mathrm{MPa}, \mathrm{E}_{1} / \mathrm{E}_{2}=25$, $\mathrm{G}_{12} / \mathrm{E}_{2}=\mathrm{G}_{13} / \mathrm{E}_{2}=0.6, \mathrm{G}_{23} / \mathrm{E}_{2}=0.5, \mathrm{v}=0.25$. The number of terms that taken into account in the $\mathrm{m}$ and $\mathrm{n}$ cycle is seven (i.e. $\mathrm{m}=7$ and $\mathrm{n}=7$ ).

A uniformly distributed step impulsive load, $\mathrm{q}_{\mathrm{o}}=2000 \mathrm{~N} / \mathrm{m}^{2}$, is applied on the shell. The influences of R/a and foundation parameters on the forced vibration of the anti-symmetrically LCS under time-dependent load are investigated. In this part, Laplace transform parameter $(\mathrm{N}=512)$ and time increment value of $(\mathrm{dt}=0.0001)$ have been used.

Forced vibration analysis for anti-symmetrically thick LCS on elastic foundation under time-dependent load with different values of $R / a$ and foundation parameters when the $E_{1} / E_{2}$ is kept constant at 25 are given in Figs. 6-7. It might be observed in figures that rises in foundation parameters cause to a decrease on the displacement and stress amplitude for antisymmetrically laminated thick shells on elastic foundation. Also, decrease of R/a ratio disappeared the effect of Winkler parameter on the displacement amplitude. When the vertical displacement values corresponding to the maximum points on the curves are compared to each other, it can be seen from Figure 5 that the vertical displacements values on maximum points of curves decrease when the foundation parameters change from $\left(\mathrm{k}_{0}=0, \mathrm{k}_{1}=0\right)$ to $\left(\mathrm{k}_{0}=100, \mathrm{k}_{1}=0\right)$. The curve decreases a little more when the foundation parameters change from $\left(\mathrm{k}_{0}=0, \mathrm{k}_{1}=0\right)$ to $\left(\mathrm{k}_{0}=100, \mathrm{k}_{1}=10\right)$. Influence of Pasternak parameter on dynamic response is more prominent than Winkler parameter for the anti-symmetric laminated scheme.

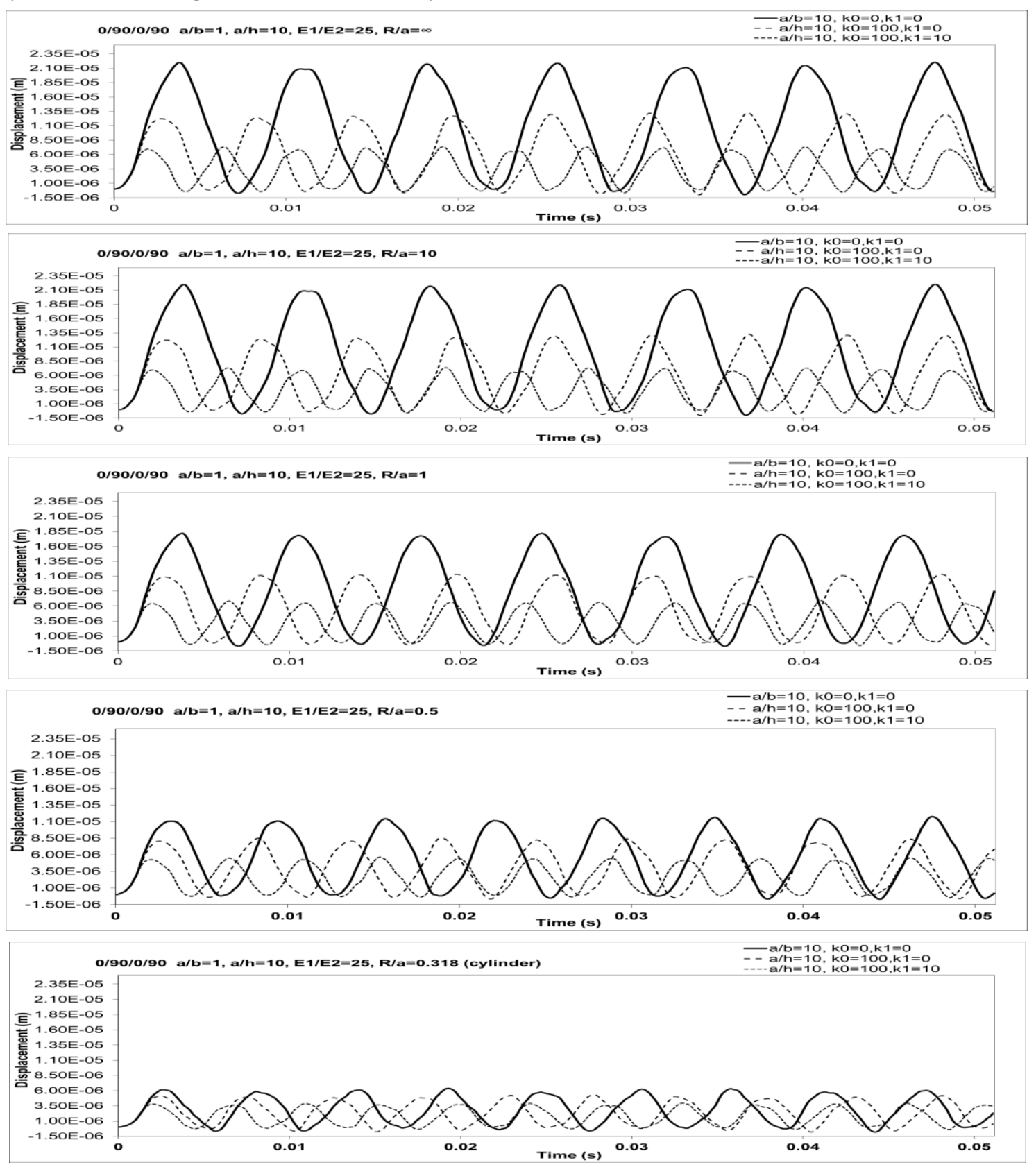

Figure 6: Effect of curvature on vertical displacement values of anti-symmetric [0/90/0/90] laminated composite shells on elastic foundation. 


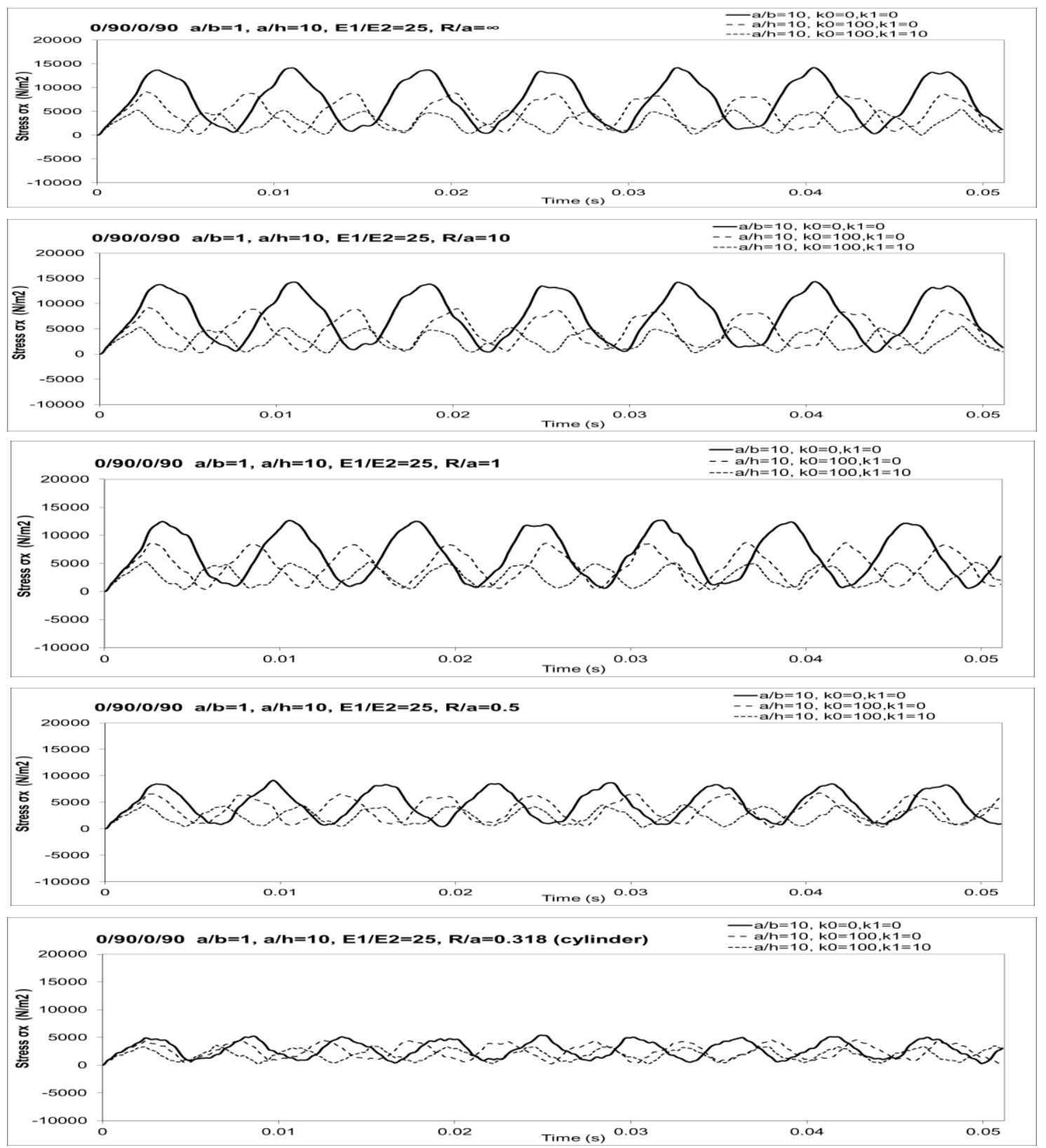

Figure 7: Effect of curvature on stress values of anti-symmetric [0/90/0/90] laminated composite shells on elastic foundation.

\section{Results}

In this study, forced vibration analyses of anti-symmetrically cross-ply laminated composite shells based on elastic foundation are investigated. The most important observations and results are summarized as follows:

Curvature ratio (R/a) is an effective parameter on the foundation stiffness, increase of $\mathrm{R} / \mathrm{a}$ ratios increased the displacement and stress values.

For the cross-ply laminated composite shells, increase of foundation parameters $\left(\mathrm{k}_{0}\right.$ and $\left.\mathrm{k}_{1}\right)$ decreased the displacement and stresses values.

Results also showed that $\mathrm{k}_{1}$ is more effective than that of the $\mathrm{k}_{0}$. Not only the Winkler parameter is sufficient in the in the evaluation of the laminated shells on elastic foundation, but also Pasternak parameter have to taken into account.

\section{References}

[1] Durbin F. "Numerical inversion of laplace transform: An efficient improvement to dubner and abate's method". Computer Journal, 17(4), 371-376, 1974.

[2] Reissner E. "The effect of transverse shear deformation on the bending of elastic plates". Journal of Applied Mechanics, 12, 69-77, 1945.

[3] Lee YS, Choi MH, Kim J H. "Free vibrations of laminated composite cylindrical shells with an interior rectangular plate". Journal of Sound and Vibration, 265 (4), 795-817, 2003.

[4] Dogan A, Arslan HM. "Investigation of the effect of shell plan-form dimensions on mode-shapes of the laminated composite cylindrical shallow shells using SDSST and FEM". Steel and Composite Structures, An Int|'l Journal, 12(4), 303-24, 2012. 
[5] Dogan A. Free Vibration Analysis of Laminated Composites Plates and Cylindrical Shallow Shells". Ph.D. Thesis, Çukurova University, Adana, Turkey, 2009.

[6] Dogan A, Arslan HM, Yerli HR. "Effects of anisotropy and curvature on free vibration characteristics of laminated composite cylindrical shallow shells". Structural Engineering and Mechanics, 35, 493-510, 2010.

[7] Lee YS, Choi MH, Kim JH. "Free vibrations of laminated composite cylindrical shells with an interior rectangular plate". Journal of Sound and Vibration, 265(4), 795-817, 2003.

[8] Sofiyev AH. "The buckling of a cross-ply laminated nonhomogeneous orthotropic composite cylindrical thin shell under time dependent external pressure". Structural Engineering and Mechanics, 14, 661-677, 2002.

[9] Qatu MS. Vibration of Laminated Shells and Plates. Netherlands, Elsevier, 2004

[10] Reddy JN. Mechanics of Laminated Composite Plates and Shells: Theory and Analysis. USA, CRC Press, 2003.

[11] Toh SL, Gong SW, Shim VPW. "Transient stresses generated by low velocity impact on orthotropic laminated cylindrical shells". Composite Structures., 31(3), 213-228, 1995.

[12] Temel B, Sahan MF. "Transient analysis of orthotropic viscoelastic thick plates in Laplace domain". European Journal of Mechanics. -A/Solid, 37, 96-105, 2013.
[13] Hui-Shen S, Zheng JJ, Huang XL. "Dynamic response of shear deformable laminated plates under thermomechanical loading and resting on elastic foundations". Composite Structures, 60, 57-66, 2003.

[14] Pasternak PL. "New method calculation for flexible substructures on two-parameter elastic foundation". Gosudarstvennogo Izdatelstoo, Literatury po Stroitelstvui Architekture, Moskau 1954.pp. 1-56, 1954 (in Russian).

[15] Akavci SS, Yerli HR. Dogan A. "The first order shear deformation theory for symmetrically laminated composite plates on elastic foundation". The Arabian Journal for Science and Engineering, 32(2B), 341-8, 2007.

[16] Civalek Ö. "Nonlinear dynamic response of laminated plates resting on nonlinear elastic foundations by the discrete singular convolution-differential quadrature coupled approaches". Composite Part B: Engineering, 50, 171-79, 2013.

[17] ANSYS. "Theory Reference Manual and ANSYS Element Reference". http://www.ansys.com (10.06.2017).

[18] MATHEMATICA."Wolfram Research." http://www.wolfram.com/ (10.06.2017). 